\title{
Conhecimento de discentes do ensino médio, de escola pública, acerca do papilomavírus humano
}

\author{
Knowledge of public school high school discents, about human papillomavirus \\ Conocimiento de estudiantes de escuela secundaria, escuelas públicas, sobre el papilomavirus
}

humano

Recebido: 11/06/2021 | Revisado: 19/06/2021 | Aceito: 02/07/2021 | Publicado: 14/07/2021

Gabrielly Laís de Andrade Souza

ORCID: https://orcid.org/0000-0003-2078-9574 Centro Universitário Maurício de Nassau, Brasil

E-mail: gabriellyandrade.enf52@gmail.com

Manoel Felipe Nunes da Rocha

ORCID: https://orcid.org/0000-0001-5325-888X Centro Universitário Maurício de Nassau, Brasil

E-mail: manoelfelipeenfermeiro@gmail.com

Germana Maria dos Santos

ORCID: https://Orcid.org/0000-0001-5726-7900 Centro Universitário Maurício de Nassau, Brasil E-mail: germanass369@gmail.com

Monalis Fernanda Soares Silva ORCID: https://orcid.org/0000-0002-6795-2829 Centro Universitário Maurício de Nassau, Brasil E-mail: monalisfernanda@gmail.com Gabriela de Pontes Siqueira ORCID: https://orcid.org/0000-0001-9669-7882 Centro Universitário Maurício de Nassau, Brasil E-mail: gabi.17pontes@hotmail.com

\begin{abstract}
Resumo
Introdução: Segundo a Organização Mundial de Saúde (OMS), adolescência constitui-se como uma etapa do desenvolvimento humano e período de vulnerabilidade para contaminação por Infecções Sexualmente Transmissíveis (IST), destacando-se o Papiloma Vírus Humano (HPV), que atinge 82\% dos adolescentes. Objetivo: Buscar compreender conhecimento de discentes do ensino médio, de escola pública, acerca do HPV. Método: Trata-se de um estudo do tipo descritivo, de corte transversal com abordagem quantitativa, que ocorreu em duas etapas, onde participaram 58 discentes. Resultados: 94,1\% responderam que já ouviram falar do HPV e 5,9\% que não. O conhecimento dos discentes sobre o HPV tem relação com o ambiente escolar, visto que 84,3\% relataram que já tiveram palestras na escola. Conclusão: É notório o conhecimento mínimo dos adolescentes sobre o HPV e a importância da escola na construção de conhecimento e promoção da saúde, bem como, a baixa participação das unidades de saúde neste processo.

Palavras-chave: Atenção básica; Educação em saúde; Infecções sexualmente transmissíveis; Papiloma Vírus Humano (HPV).
\end{abstract}

\begin{abstract}
Introduction: According to the World Health Organization (WHO), adolescence constitutes a stage of human development and a period of vulnerability for contamination by Sexually Transmitted Infections (STIs), highlighting the Human Papilloma Virus (HPV), which reaches $82 \%$ of adolescents. Objective: To seek to understand the knowledge of high school and public school students about HPV. Method: This is a descriptive, cross-sectional study with a quantitative approach, which took place in two stages, in which 58 students participated. Results: $94.1 \%$ answered that they had heard of HPV and 5.9\% that they did not. The students' knowledge about HPV is related to the school environment, since $84.3 \%$ reported that they had already had lectures at school. Conclusion: The adolescents' minimum knowledge about HPV and the importance of the school in the construction of knowledge and health promotion are notorious, as well as the low participation of health units in this process.
\end{abstract}

Keywords: Primary care; Health education; Sexually transmitted infections; Human Papilloma Virus (HPV).

\section{Resumen}

Introducción: Según la Organización Mundial de la Salud (OMS), la adolescencia constituye una etapa del desarrollo humano y un período de vulnerabilidad a la contaminación por Infecciones de Transmisión Sexual (ITS), destacando 
el Virus del Papiloma Humano (VPH), que afecta al 82\% de los adolescentes. Objetivo: Buscar comprender el conocimiento de los estudiantes de secundaria de las escuelas públicas sobre el VPH. Método: Se trata de un estudio descriptivo, transversal con enfoque cuantitativo, que se desarrolló en dos etapas, en el que participaron 58 estudiantes. Resultados: el 94,1\% respondió que había oído hablar del VPH y el 5,9\% que no. El conocimiento de los estudiantes sobre el VPH está relacionado con el entorno escolar, ya que el 84,3\% informó que ya ha tenido clases magistrales en la escuela. Conclusión: Es notorio el conocimiento mínimo de los adolescentes sobre el VPH y la importancia de las escuelas en la construcción de conocimientos y promoción de la salud, así como la baja participación de las unidades de salud en este proceso.

Palabras clave: Atención primaria; Educación para la salud; Infecciones de transmisión sexual; Virus del papiloma humano (VPH).

\section{Introdução}

A adolescência é compreendida pela Organização Mundial de Saúde (OMS) como uma etapa importante e fundamental do desenvolvimento humano, sendo caracterizada como um período de crescimento heterogêneo, no qual o indivíduo passa por grandes vivências, desafios, expectativas, transformações e descobertas, que ocorre na segunda década de vida, que vai dos 10 aos 19 anos de idade, marcando a passagem da infância à vida adulta (Sá et al. 2015; Carvalho et al. 2018).

As mudanças e transformações inerentes a construção da adolescência, sejam elas a nível físico, cognitivo e psicossocial, trazem consigo também, condições intrínsecas e extrínsecas que expõem os adolescentes a diversas situações de vulnerabilidade, como a contaminação por Infecções Sexualmente Transmissíveis (IST). Principalmente, por ser nessa fase que se inicia a descoberta da sexualidade e das práticas sexuais, que muitas das vezes ocorrem de maneira precoce, errônea e sem nenhuma proteção (Gomes et al. 2013; Costa et al. 2019).

Embora as IST possam acometer pessoas de diferentes faixas etárias, a sua maior incidência e prevalência encontra-se entre os adolescentes de 15 a 19 anos, destacando-se o Papiloma Vírus Humano (HPV) como sendo uma das IST com maiores taxas de prevalência cumulativas, chegando a atingir $82 \%$ dos adolescentes, concentrando-se, principalmente, em adolescentes do sexo feminino (Costa et al. 2019).

O Ministério da Saúde em parceria com o Hospital Moinhos de Vento realizou, por meio do projeto Pop Brasil, um estudo epidemiológico sobre a Prevalência Nacional de Infecção pelo HPV em todas as capitais brasileiras e no Distrito Federal. O estudo foi realizado com 7.586 participantes, sendo que mais de $70 \%$ do público participante da pesquisa era composto pelo sexo feminino, enquanto os participantes do sexo masculino representavam menos de $25 \%$ desse total, de acordo com os dados preliminares, o estudo mostrou uma predominância geral estimada de exposição à infecção pelo HPV em 54,6\% dos participantes e 38,4\% dos mesmos apresentaram HPV de alto risco para o desenvolvimento de câncer (Hohenberger, 2017).

Decorrente disso, vale ressaltar que o HPV é um vírus com grande potencial oncogênico para o desenvolvimento de alguns tipos de neoplasias, principalmente, de colo de útero, pênis e ânus. Atualmente já foram identificados mais de 200 subtipos distintos de HPV e cerca de 45 destes podem infectar o epitélio do trato anogenital, tanto feminino quanto masculino. Os mesmos são divididos de acordo com seu grau oncogênico, sendo os de baixo risco os subtipos 6, 11, 42, 43 e 44, e os de alto risco os subtipos 16, 18, 31, 33, 35, 58, 59 e 68 (Chaves et al. 2011; Silva, 2015).

A infecção pelo vírus do HPV pode ocorrer principalmente por contato sexual, mas também durante o período gestacional ou no momento do parto por gestantes contaminadas. As manifestações clínicas ocorrerão de acordo com o tipo de infecção, que pode ser clínica, subclínica ou latente, as manifestações clínicas são as mais comuns e visíveis a olho nu, que são os condilomas acuminado ou "crista-de-galo", porém o tipo de infecção subclínica é o que mais prevalece, chegando a $80 \%$ dos casos de infecção pelo HPV e suas manifestações não são visíveis a olho nu (Chaves et al. 2011). 
De acordo com o Ministério da Saúde (MS) e o Instituto Nacional do Câncer (INCA), existem alguns meios de diagnosticar a presença de infecção pelo HPV. Pode ser através de exames clínicos (urológico, ginecológico e dermatológico) e laboratoriais (peniscopia, anuscopia, biópsias e Histopatologia). Ainda de acordo com o MS o tratamento para combater a infecção pelo HPV pode ser realizado por eletro cauterização, ácido tricloroacético, laser e imiquimode, esses tratamentos variam a depender de alguns fatores, como tipo e localização da lesão, extensão e quantidades de lesões (Brasil, 2019; Inca, 2019).

O Ministério da Saúde destaca que um dos principais meios de combater a infecção pelo HPV é através de medidas preventivas como a vacinação de meninas de 9 a 14 anos e meninos de 11 a 14 anos, uso de preservativos nos atos sexuais e educação em saúde, tendo em vista que o período da adolescência representa uma maior vulnerabilidade, além de ser um período de construção do conhecimento, principalmente, no âmbito das IST, tornando-se, dessa forma, um período propício para realização da prevenção (Sá et al. 2015; Brasil, 2019).

Já no que é relacionada à educação em saúde, direcionada para adolescentes, no contexto de prevenção de IST, a literatura evidencia que, o ambiente escolar é fundamental para o desenvolvimento dessa prática, por se tratar de um local que estimula constantemente o processo de aprendizagem e o desenvolvimento do pensamento crítico, além de ser um ambiente propício e de grande relevância na educação sexual desses adolescentes, corroborando com outros estudos, que ressalta o ambiente escolar como sendo um espaço de grande potencial na educação em saúde de crianças e adolescentes (Santiago et al. 2012; Ataliba \& Mourão, 2018).

A literatura ressalta que, para se trabalhar educação em saúde na escola deve sempre considerar o conhecimento prévio que os discentes possuem, para que assim possam ser escolhidas as melhores metodologias para serem utilizadas com o grupo, preservando sempre a autonomia dos alunos, para que a partir disso os mesmos adquiram habilidades suficientes para o desenvolvimento de atitudes e práticas benéficas à saúde (Brasil, 2015).

Dessa forma, o Programa de Saúde na Escola (PSE) é de extrema relevância, quando implantado nas escolas, no processo de prevenção das IST e no combate das principais vulnerabilidades desse público (Ataliba \& Mourão, 2018). O mesmo trata-se de uma pactuação intersetorial entre Ministério da Educação juntamente com o Ministério da Saúde, com objetivo de contribuir para melhorar a qualidade de vida e auxiliar no desenvolvimento saudável das crianças e adolescentes (Santiago et al. 2012).

Assim, o estudo tem como objetivo buscar compreender conhecimento de discentes do ensino médio de escola pública, de uma cidade do interior de Pernambuco, acerca do HPV, no intento de auxiliar as autoridades locais para o desenvolvimento de atividades educativas com enfoque no tema, consequentemente, de forma indireta, instigar o empoderamento da comunidade acerca do assunto, para que assim seja possível o desenvolvimento de medidas corretas de prevenção, bem como, elaboração de novas ações de saúde com enfoque na educação em saúde.

\section{Metodologia}

Trata-se de um estudo do tipo descritivo de corte transversal com abordagem quantitativa, que buscou compreender o conhecimento de adolescentes, de ambos os sexos, sobre o HPV, o qual foi desenvolvido em turmas de $1^{\circ} ; 2^{\circ}$ e $3^{\circ}$ anos do ensino médio de uma instituição pública de ensino localizada na cidade de Calçado, interior de Pernambuco, em julho de 2020 sob a supervisão dos pesquisadores e de um funcionário da instituição.

Por se tratar de um estudo do tipo descritivo, a realidade e o objeto de estudo são apenas observados e descritos pelo pesquisador, sem que o mesmo faça qualquer interferência em sua realidade. Sendo que um de seus principais objetivos é o conhecimento acerca de um determinado assunto de uma população específica, que pertinentemente se caracteriza como uma situação potencialmente desconhecida (Aragão, 2011). 
Além do mais, de acordo com a literatura, pesquisas com corte transversal têm como objetivo a visualização de uma população em um tempo específico, de forma que não investiga tal situação anteriormente ou posteriormente, isso possibilita ter um conhecimento em tempo real sem possíveis interferências. Ademais, a abordagem quantitativa adota a avaliação de variáveis de forma mais sistemática e com senso que leva a dedução dos critérios apresentado de maneira mais precisa e generalizada, conforme as questões apresentadas à população. Além do mais, os estudos quantitativos não perderam sua força, na atualidade, mesmo depois que as pesquisas qualitativas se tornaram cada vez mais frequentes. (Sousa et al. 2007; Aragão, 2011).

A pesquisa foi realizada em duas etapas, sendo a primeira destinado à realização do convite aos discentes através do grupo específico do WhatsApp, enquanto a segunda, foi destinado a assinatura e concordância do termo de consentimento livre esclarecido (TCLE), termo de assentimento livre e esclarecido (TALE) e aplicação do instrumento de coleta, que poderia ser acessado através do link disponibilizado pelos pesquisadores no grupo de WhatsApp, já mencionado anteriormente.

Dessa forma, a coleta dos dados foi realizada através da aplicação de questionário fechado, composto por nove questões, cada questão possuía no mínimo duas e no máximo cinco alternativas, dentre elas, só uma estando correta, além de três questões referente ao perfil do estudante (série; idade e sexo) que foi preenchida pelos educandos, atendendo de tal forma a Resolução 510/16 e 466/12 do Conselho Nacional de Saúde.

$\mathrm{O}$ instrumento de coleta além de atender ao critério de classificação, por se tratar de uma pesquisa com abordagem quantitativa, sendo esse o instrumento ideal para a realização da pesquisa a qual foi desenvolvida, teve como objetivo buscar responder a questão norteadora da pesquisa, a qual se formulou da seguinte forma: De que maneira os estudantes do ensino médio, da escola pública, da cidade de Calçado, compreendem a infecção pelo Papilomavírus Humano (HPV)?. Vale salientar que devido a atual situação vivenciada pelo mundo, decorrente do novo coronavírus, o COVID-19, a pesquisa foi desenvolvida de forma on-line por meio da plataforma do Google Formulário. Sendo assim, o instrumento de coleta ficou disponível por 6 dias, através da plataforma do google formulários, a qual foi programada para receber apenas uma resposta do discente sem direito a adição após envio.

Visto isso, participaram da pesquisa 58 discentes, o critério utilizado foi o método por conveniência. Após aplicação dos critérios de inclusão e exclusão, restaram apenas 51, os quais responderam o instrumento de coleta de maneira adequada e completa, onde estes foram analisados e interpretados através da plataforma do Google Formulário e do Microsoft Excel, servido como material para formulação e conclusão deste estudo.

Desse modo, elencaram-se os seguintes critérios de inclusão: Alunos de ambos os sexos; na faixa etária de 15 a 18 anos de idade; residentes no município de Calçado; regularmente matriculados no $1^{\circ} ; 2^{\circ}$ ou $3^{\circ}$ ano do ensino médio, na modalidade integral ou semi-integral, da escola pública. Excluíram-se, discentes com grau de parentesco familiar com algum membro da equipe responsável pela pesquisa; que estavam matriculados, porém ausentes no dia e horário da coleta dos dados por motivos de saúde; e educandos que apresentam problemas cognitivos que os impossibilitaram de responder o instrumento de coleta de maneira adequada.

Por fim, vale elencar que esta pesquisa foi aprovada pelo Comitê de Ética e Pesquisa da Autarquia Educacional de Belo Jardim - AEB, sob o parecer de $\mathrm{n}^{\circ} 4.009 .178$, e que em todas as etapas da pesquisa foi assegurado aos educandos o anonimato, a confidencialidade dos dados pessoais e a utilização das informações somente para fins científicos, atendendo a Resolução 510/16 e 466/12 do Conselho Nacional de Saúde.

\section{Resultados e Discussão}

Entender e avaliar o conhecimento de adolescentes sobre o Papilomavírus Humano (HPV) e suas complicações é de extrema relevância, tendo em vista que as maiores taxas de prevalência concentra-se neste grupo, além de que a visão deste 
conhecimento por profissionais da saúde possibilita a criação de estratégias assertivas que vise medidas de promoção da saúde e prevenção de agravos, bem como, diagnósticos precoces de possíveis alterações e complicações que possam ser provocadas pelo vírus do HPV, como o câncer de colo do útero e ânus, mais comum, respectivamente, no sexo feminino e masculino (Sousa et al. 2014; Abreu et al. 2018).

Dessa forma, com a finalidade de buscar compreender o conhecimento dos adolescentes acerca do HPV, foi realizada uma pesquisa em uma escola de ensino médio, localizada na cidade de calçado, interior de Pernambuco. Na qual participaram 51 discentes, sendo $68,6 \%$ do sexo feminino e $31,4 \%$ do sexo masculino. Os mesmos quando agrupados pelas variáveis de sexo, idade e série, apresentaram-se conforme ilustrado no Quadro 1.

Quadro 1: Distribuição dos participantes de acordo com as variáveis de sexo, idade e série.

\begin{tabular}{|cccc|}
\hline Variáveis & Categoria & $\mathbf{N}^{\circ}$ & \% \\
\hline \multirow{2}{*}{ Sexo } & Feminino & 35 & 68,6 \\
& Masculino & 16 & 31,4 \\
\hline \multirow{2}{*}{ Idade } & 15 anos & 10 & 19,6 \\
& 16 anos & 26 & 51 \\
& 17 anos & 11 & 21,6 \\
Série & 18 anos & 4 & 7,8 \\
\hline & $1^{\circ}$ & 3 & 5,9 \\
& $2^{\circ}$ & 32 & 62,7 \\
& $3^{\circ}$ & 16 & 31,4 \\
\hline
\end{tabular}

Fonte: Autores (2020).

Verificou-se que a maioria dos discentes que participaram da pesquisa eram do sexo feminino, chegando a representar mais de $60 \%$ do total de educandos, enquanto o sexo masculino representou menos de $40 \%$. Essas porcentagens vão de encontro com dados de outros estudos, os quais evidenciam o público feminino como sendo o mais ativo e participante, estando estes fatos relacionados a diversos fatores, dentre eles, o interesse pela temática (Pinheiro \& Cadete, 2019).

Os alunos quando questionados sobre já ter ouvido falar sobre o HPV, 94,1\% responderam que sim e apenas 5,9\% relataram que nunca tinham ouvido falar sobre o vírus. Esses dados vão, em desencontro com outros estudos, como o realizado por Abreu, o qual indaga que os adolescentes e a comunidade em geral ainda possuem grande déficit no nível de conhecimento a respeito do HPV, estando este fato relacionado há pouca qualificação, bem como ao baixo investimento em novas ações de educação em saúde (Abreu et al. 2018).

O conhecimento elevado dos discentes sobre o HPV tem relação direta com ambiente escolar, bem como professores e profissionais da saúde, em especial, enfermeiros(as). Ao que concerne o questionamento sobre já terem tido palestras dentro do ambiente escolar que abordasse a temática, $84,3 \%$ falaram que sim e apenas 15,7\% relataram que não, desses que responderam sim, quando questionados sobre quem realizou essas palestras, responderam conforme ilustrado no Gráfico 1. 
Gráfico 1: Percentual de profissionais que já realizaram palestras no ambiente escolar.

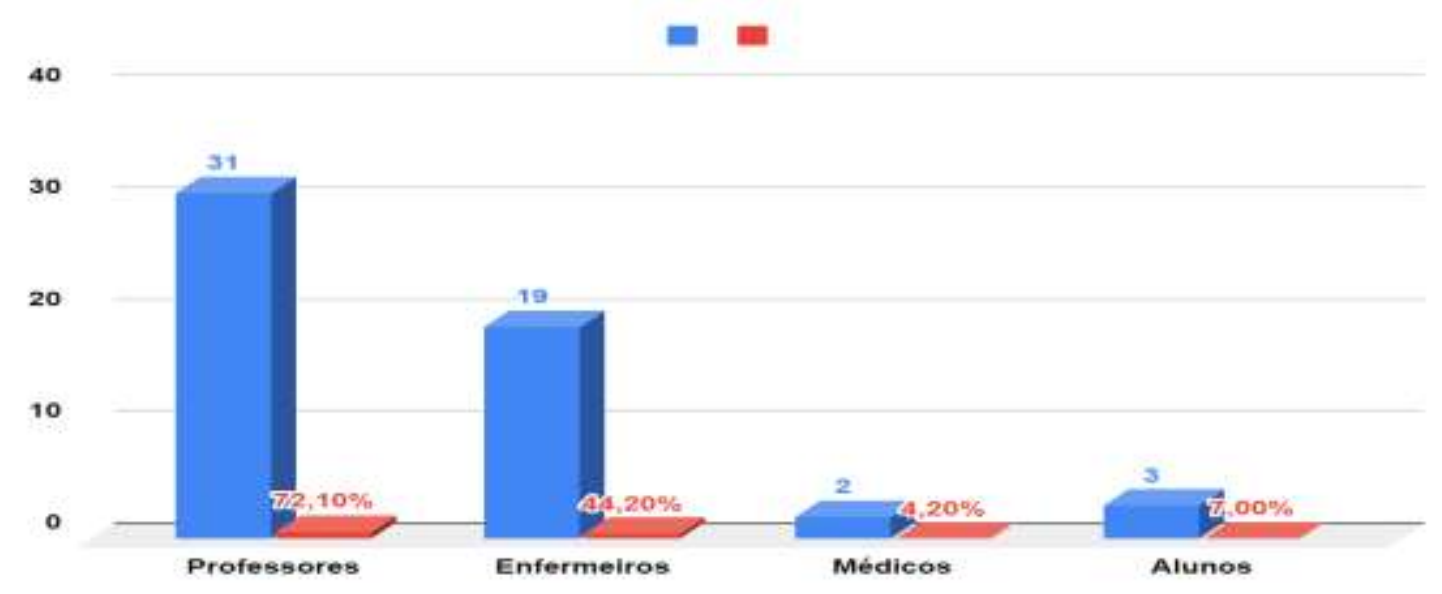

Fonte: Autores (2020).

Por isso é de suma importante instigar a execução de novas ações de educação em saúde, principalmente no ambiente escolar, por professores e profissionais da saúde, visando proporcionar conhecimento para os adolescentes a respeito do HPV e outras ISTs, tendo em vista que estes são, de fato, a população com maior taxa de prevalência de infecção por HPV. Dessa forma, fazendo-se necessário avaliar seus conhecimentos sobre essa temática com vista a adequação das medidas de promoção e proteção da saúde sexual e reprodutiva, bem como, a desconstrução de conhecimentos errôneos, evitando assim a propagação do vírus (Sousa et al. 2014).

Tais resultados se consolidam como satisfatórios à medida que as etapas da pesquisa vão avançando. Isso fica claro quando os discentes respondem às seguintes perguntas: "Você sabe o que é HPV?" e 88,2\% responderam que sim e apenas 11,8\% que não. Destes educandos que responderam ter conhecimento sobre o que é o vírus do HPV, quando questionados do que se tratava, $93,3 \%$ responderam que se trata de um vírus, enquanto 4,4\% que era um protozoário e apenas 2,2\% do total de participantes do estudo responderam que se trata de uma bactéria. Por fim, quando questionados sobre "o que é considerado o HPV?" Mais de 90\% responderam de forma assertiva que é considerado uma ISTs e menos de $8 \%$ responderam que era uma virose, diarreia ou outros.

Neste contexto, é notório que a divulgação de informações e o trabalho eficaz de educação em saúde realizado por professores, enfermeiros e outros profissionais da saúde dentro do ambiente escolar promove o enriquecimento do conhecimento dos discentes sobre cuidados à saúde sexual e reprodutiva associada à conscientização dos mesmos quanto aos riscos e vulnerabilidades que eles possam vir a se expor, como as ISTs (Pinheiro \& Cadete, 2019).

Sendo assim, o ambiente escolar torna-se essencial na construção do conhecimento e realização de ações de educação em saúde direcionado para os adolescentes, levando em consideração que os mesmos permanecem a maior parte do seu tempo na escola em busca de construção do saber e socialização. Dessa forma, ações com essas características tornam-se estratégias de promoção da saúde e qualidade de vida, além de formar adolescentes e adultos conscientes, autônomos e responsáveis (Pinheiro \& Cadete, 2019).

Em seguida, os discentes quando indagados sobre quais os principais meios de contrair o HPV, 96,1\% responderam que o vírus pode ser contraído por meio das relações sexuais desprotegidas e apenas 3,9\% relataram que poderia se contaminar através do beijo e do ar. Estudos demonstraram que a infecção decorre principalmente do contato sexual sem proteção, que permite, por meio de micro abrasões, a penetração do vírus na camada profunda do tecido epitelial, podendo se dar pelo 
contato direto ou indireto com as lesões em outras partes do corpo, além de ser descrita a transmissão vertical durante a gestação ou no momento do parto (Abreu et al. 2018).

Segundo Primo, o HPV na grande maioria das vezes tem a chance de $95 \%$ de transmissão por meio do contato direto nas relações sexuais e mesmo não sendo possível definir com autenticidade o seu poder de contaminação por fômites, o HPV tem 5\% de transmissibilidade com alguém que tem a forma clínica ou subclínica, desde que haja secreção com o vírus vivo, como por exemplo o compartilhamento de objetos inanimados como sabonete, toalhas, roupas íntimas, escova de dentes, vaso sanitário, dentre outros (Primo \& Primo, 2019).

Os estudantes quando indagados sobre a sintomatologia da IST, 74,5\%, o equivalente a 38 participantes, responderam que os principais sinais e sintomas do vírus são caracterizados pelas verrugas, enquanto 17,7\% responderam que são dores de cabeça e falta de ar e apenas 7,8\% marcaram que o questionário não tinha nenhuma alternativa correta, esse percentual pode estar relacionado ao baixo desinteresse dos discentes pela temática, bem como, a ausência dos mesmos em eventos intra e extra escolar que abordasse a este tipo de assunto.

De acordo com alguns estudos a infecção pelo vírus do HPV pode apresentar-se de forma clínica, subclínica ou latente, sendo o sinal mais comum da presença do vírus no organismo o condiloma genital ou verruga, podendo essas eclodirem, principalmente, próximo das regiões genitais, tanto masculina, quanto feminina ${ }^{17}$. Os autores ainda ressaltam que a grande maioria das infecções por HPV são assintomáticas e autolimitadas e que as formas subclínica e latente só podem ser diagnosticadas através de exames, como: citologia, colposcopia ou testes de biologia molecular, diferente da forma clínica, que pode ser diagnostica a olho nu (Primo \& Primo, 2019).

Os discentes também foram indagados sobre quais as principais formas de tratamento utilizadas para combater a infecção pelo HPV. E apenas 23,5\% mostraram conhecimento satisfatório frente a este questionamento, respondendo que procedimentos cirúrgicos seriam a alternativa correta, frente às demais alternativas, sendo ainda que $2 \%$ dos participantes relataram que o antifúngico pode ser usado no tratamento de infecção pelo HPV, como ilustrado pelo Gráfico 2.

Gráfico 2: Respostas dos discentes frente ao questionamento "Quais as formas de tratamento?".

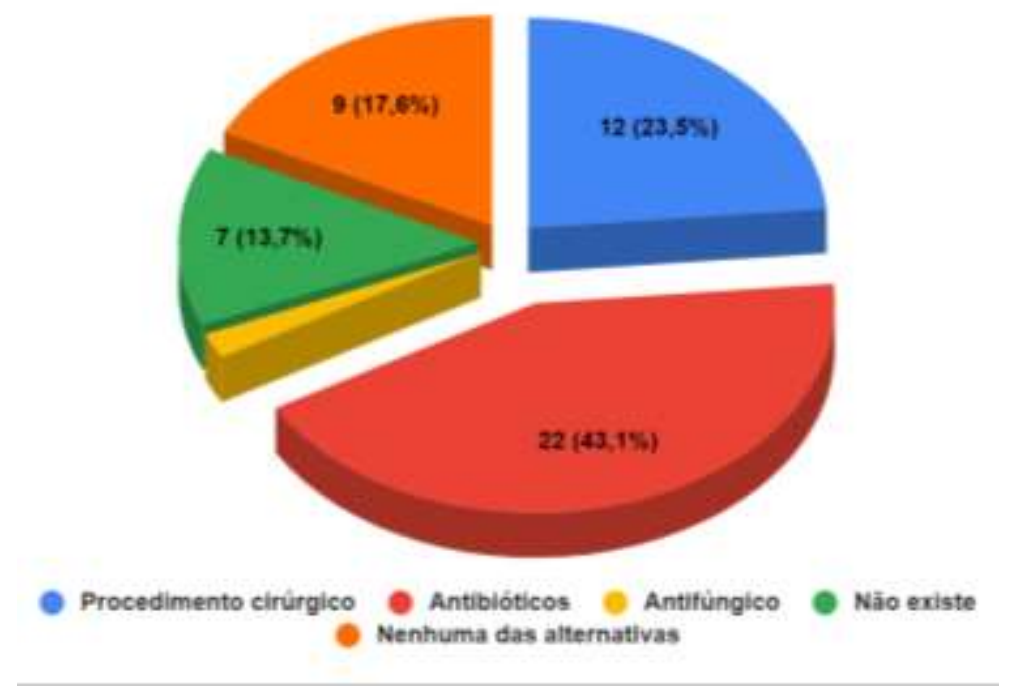

Fonte: Autores (2020).

Segundo dois estudos, existem alguns fatores que podem influenciar na escolha do tratamento, como a morfologia, tamanho, número e local anatômico onde a lesão se encontra, mas no geral os tratamentos podem ser tópicos, por meio de 
agentes químicos, físicos, imunomoduladores ou incisionais, e/ou sistêmicos, o qual pode ser aplicado pelo paciente ou dependente de aplicação médica (Brás et al. 2015; Primo \& Primo, 2019).

Os mesmos ainda ressaltam que não existe terapia antiviral específica para tratar a infecção causada pelo HPV e que os tratamentos disponíveis são para as condições causadas pelo mesmo, e não contra o vírus propriamente dito. Dessa forma, o propósito do tratamento é atuar sobre as lesões detectáveis no sentido de estimular o sistema imunológico do paciente e prevenir a transmissão e complicações (Brás et al. 2015; Primo \& Primo, 2019).

Assim, os discentes quando questionados sobre as principais complicações decorrentes do HPV responderam conforme ilustrado no Gráfico 3. Sendo que $2 \%$ responderam que a cegueira pode ser uma complicação decorrente da infecção pelo HPV.

Gráfico 3: Visão dos discentes sobre as principais complicações que podem ser causadas pelo HPV.

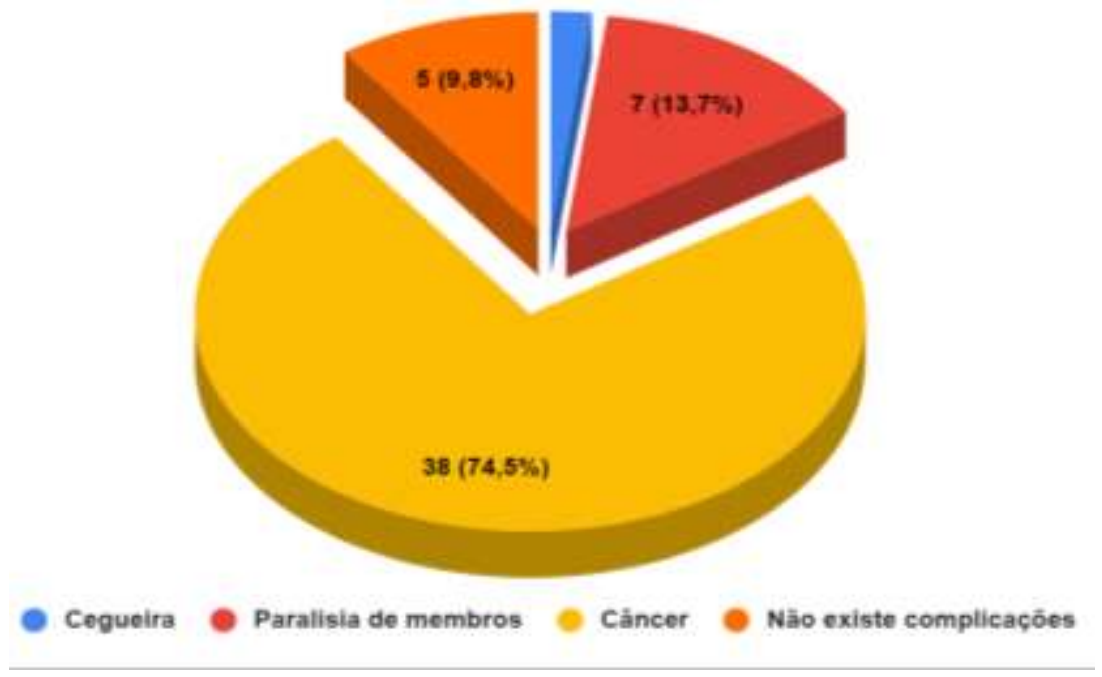

Fonte: Autores (2020).

De acordo com Carvalho as infecções pelo vírus do HPV tem relação direta com o câncer, principalmente do colo de útero $^{19}$, sendo este, de acordo com o INCA, o terceiro câncer mais frequente na população feminina brasileira, onde estima-se a incidência de mais de 16 mil casos para cada ano do biênio 2018-2019, os quais podem ser detectados de maneira precoce através da realização do exame Papanicolau, conhecido também como preventivo do câncer do colo do útero (INCA, 2017), o qual, segundo Rodrigues, é considerado o procedimento de maior sucesso no controle de câncer cervical, sendo observado uma redução de 70\% nos casos clínicos (Rodrigues \& Sousa, 2015).

Por fim, os discentes foram questionados sobre as principais maneira de prevenção que podem ser adotados para não se infectar pelo vírus, e 94,1\% responderam que a melhor forma de prevenir a infecção, consequentemente, a disseminação do vírus, seria o uso do preservativo interno ou externo durante o ato sexual, bem como, a vacinação de meninas de 9 a 14 anos e meninos de 11 a 14 anos; e apenas 5,9\% dos participantes do estudo responderam que as medidas preventivas seriam uso de anticoncepcionais ou PrEP (Profilaxia Pré-Exposição).

De acordo com estudos, semelhante a este, o uso do preservativo interno ou externo durante as relações sexuais é considerado o principal método preventivo contra a infecção do HPV, bem como, a vacinação de meninos de 11 a 14 anos e meninas de 09 a 14 anos que não iniciaram a vida sexual, as quais foram introduzidas em todo o mundo desde $2006 \mathrm{e}$ apresentaram um alto registro de eficácia e segurança na prevenção de infecções e das doenças HPV-induzidas, por seguinte representam melhor forma de prevenção primária (Rodrigues \& Sousa, 2015; Primo \& Primo, 2019). 
Assim, mesmo com a existência da vacina contra o HPV, é de extrema importância a realização de ações de cunho educativo, educação em saúde, sobre sexualidade, IST e outras assuntos que possam auxiliar no processo de prevenção da infecção pelo vírus, bem como, a quebra da cadeia de propagação do mesmo (Primo \& Primo, 2019).

\section{Conclusão}

Por meio deste estudo foi possível entender o conhecimento dos discentes sobre o HPV, os quais mostraram resultados satisfatórios frente as noções básicas desta IST, como: conceito; características; tratamento; transmissão; bem como, sinais e sintomas, mostrando de tal forma, um conhecimento mínimo, dos adolescentes sobre a infecção, fato este, que é de extrema relevância, tendo em vista que o conhecimento auxilia na desconstrução de conceitos errôneos, consequentemente, na prevenção de doenças e promoção da saúde.

É notório que a escola tem um papel fundamental na construção de conhecimento e promoção da saúde, fato este, que fica claro no estudo, tendo em vista que a mesma se mostrou ativa frente à temática. Vale ressaltar que a participação da escola não anula a participação das unidades de saúde, as quais se mostram pouco ativas nesses ambientes, tornando-se um ponto preocupante, levando em consideração que estas possuem como principal objetivo a educação em saúde, consequentemente, a prevenção de doenças.

Dessa forma, por mais que positivo os resultados, se faz necessário estudos mais amplos que venham a abortar outras questões, como: sociais e culturas. Assim como pesquisas quem possam representar um montante maior de adolescentes do município e de outras regiões, bem como, uma maior participação e envolvimento das unidades de saúde com os mesmos, além da elaboração de estratégias e atividades que possam auxiliar as escolas e outras instituições de ensino a manter e fortalecer as ações de educação em saúde para as crianças e adolescentes.

\section{Referências}

Abreu, M. N. S. Soares, A. D. Ramos, D. A. O. Soares, F. V. Nunes, F. G \& Valadão, A. F et al., (2018). Conhecimento e percepção sobre o HPV na população com mais de 18 anos da cidade de Ipatinga, MG, Brasil. Ciênc. saúde coletiva, 23 (3), 849-860.

Aragão, J. (2011). Introdução aos estudos quantitativos utilizados em pesquisas científicas. Revista Práxis, 3 (6), 60-62.

Ataliba, P. \& Mourão, L. (2018). Avaliação de impacto do Programa Saúde nas Escolas. Psicologia Escolar e Educacional, 22 (1), $27-36$.

BRASIL. (2015). Caderno do Gestor do PSE / Ministério da Saúde, Ministério da Educação. 68.

BRASIL. (2019). Estudo apresenta dados nacionais de Prevalência da Infecção pelo HPV http://portalms.saude.gov.br/noticias/agencia-saude/42013-estudoapresenta-dados-nacionais-de-prevalencia-da-infeccao-pelo-hpv-2.

Brás, F. Sardinha, R. \& Pacheco, A. (2015). Therapeutic procedures in the treatment of condylomata acuminata Modalidades terapêuticas no tratamento dos condilomas acuminados. Acta Obstet Ginecol Port, 9 (5), 383-392.

Carvalho, K. F. Costa, L. M. O. \& França, R. F. (2019). A relação entre hpv e câncer de colo de útero: um panorama a partir da produção bibliográfica da área. Revista Saúde em Foco, (11), 264-678.

Carvalho, O. Pinto, R. G. S. \& Santos, M. S. (2018). Conhecimento sobre as infecções sexualmente transmissíveis por estudantes adolescentes de escolas públicas. Adolesc Saude 15 (1), 7-17.

Costa, M. I. F. Viana, T. R. F. Pinheiro, P. N. C. Cardoso, M. V. L. M. L. Barbosa, L. P. \& Luna, I. T. (2019). Determinantes sociais da saúde e vulnerabilidades às infecções sexualmente transmissíveis em adolescentes. Rev. Bras. Enferm, 72 (6), 1595-1601.

Chaves, J. H. B. Vieira, T. K. B. Ramos, J. S. \& Bezerra, A. F. S. (2011). Peniscopia no rastreamento das lesões induzidas pelo papilomavírus humano. Rev Bras Clin Med, 9 (1), 30-5.

Federação Brasileira das Sociedades de Ginecologia e Obstetrícia. (2002). Projeto diretrizes: Papilomavírus Humano (HPV): Diagnóstico e Tratamento http://www.febrasgo.org.br/arquivos/diretrizes/079.pdf.

Gomes, V. L. O. Acosta, D. F. Silva, C. D. Pinheiro, T. M. \& Souza, C. S. (2013). Atendimento em uma unidade básica de saúde: estudo com foco na saúde sexual de adolescentes do município de Rio Grande/RS. Enfermería Global, (31), 117-124.

Hohenberger, G. F. Caierão, J. \& Kops, N. L. (2017). Estudo Epidemiológico Sobre a Prevalência Nacional de Infecção Pelo HPV Pop-Brasil. Associação Hospitalar Moinhos de Vento - $1^{\mathrm{a}}$, ed. 
Research, Society and Development, v. 10, n. 8, e38810817075, 2021

(CC BY 4.0) | ISSN 2525-3409 | DOI: http://dx.doi.org/10.33448/rsd-v10i8.17075

Instituto Nacional De Câncer (2017). Estimativa 2018: incidência de câncer no Brasil. http://www1.inca.gov.br/rbc/n_64/v01/pdf/15-resenha-estimativa-2018incidencia-de-cancer-no-brasil.pdf.

INCA (2019). Câncer do colo do útero http://www2.inca.gov.br/wps/wcm/connect/tiposdecancer/site/home/colo_utero/hpv-cancer-perguntas-mais-frequentes.

Pinheiro, P. L. L. \& Cadete, M. M. M. (2019). El conocimiento de los adolescentes escolarizados sobre el virus del papiloma humano: revisión integrativa. Enferm. glob. 18 (56), 603-663.

Primo, W. Q. S. P. \& Primo, G. R. P. (2019). Papilomavírus humano: Aspectos Clínicos. Femina, 47 (12), 850-66.

Rodrigues, A. F. \& Sousa, J. Á (2015). Papilomavírus humano: prevenção e diagnóstico. R. Epidemiol. Control. Infec. 5 (4), 197-202.

Sá, M. I. Silva, M. T. Almeida, D. Vieira, B. \& Lima, T. (2015). Infeções sexualmente transmissíveis e factores de risco nas adolescentes e jovens: Dados de um Centro de Atendimento a Jovens. Nascer e Crescer, 24 (2), 64-69.

Santiago, L. M. Rodrigues, M. T. P. Oliveira, J. A. D. \& Moreira, T. M. M. (2012). Implantação do Programa Saúde na escola em Fortaleza-CE: atuação de equipe da Estratégia Saúde da Família. Rev. bras. enferm. 65 (6), 1026-1029.

Silva, S. S. Nakajima, G. S. Guimarães, R. A. \& Mourão, F. C. (2015). Associação entre achados histológicos sugestivos de lesões por papilomavírus humano em espécimes de hemorroidectomias. ABCD, arq. bras. cir. Dig, 28 (4), 255-257.

Sousa, C. D. Marcelo, J. Amorim, P. \& Martins, M. T. C. S. (2014). Concepção dos adolescentes sobre o hpv na escola estadual de ensino fundamental e médio de Alcantil-PB. SCIRE - Revista Acadêmico-científica, 5 (1), 1-14.

Sousa, V. D. Driessnack, M. \& Mendes, I. A. C. (2007). Revisão dos desenhos de pesquisa relevantes para enfermagem. Parte 1: desenhos de pesquisa quantitativa. Rev. Latino-Am. Enfermagem, 15 (3). 